\title{
Parent Assessment of Overall Well-Being
}

National Cancer Institute

\section{Source}

National Cancer Institute. Parent Assessment of Overall Well-Being. NCI Thesaurus.

Code C121348.

A parent's estimation of the overall impact of a disease on their child at a given time.

Typically scored on a numeric rating scale or visual analogue scale. 